УДК $681.3(031)$

Сергій Шворов, доктор технічних наук, професор Національний університет біоресурсів і природокористування

ORCID 0000-0003-3358-1297

Сергій Горбачевський, кандидат технічних наук, старший науковий співробітник Національний університет оборони України імені Івана Черняховського ORCID ID 0000-0002-4946-1604

Михайло Орда, кандидат технічних наук, старший науковий співробітник Національний університет оборони України імені Івана Черняховського ORCID ID 0000-0003-0374-3881 DOI: $10.33099 / 2617-1775 / 2020-01 / 310-317$

\title{
МЕТОДИЧНІ ЗАСАДИ ОРГАНІЗАЦІЇ ІНТЕНСИВНОЇ ПІДГОТОВКИ БОЙОВИХ ОБСЛУГ КП У НАВЧАЛЬНО-ТРЕНУВАЛЬНИХ ЦЕНТРАХ ПОВІТРЯНИХ СИЛ
}

У статті розглянуті методичні засади планування та реалізації інтенсивної підготовки бойових обслуг автоматизованих командних пунктів Повітряних Сил, практичне використання яких забезпечує підвищення ефективності проведення комплексних тренувань у навчально-тренувальних ичентрах Повітряних Сил на основі інтенсифікації відпрацюювання навчальних завдань.

Ключові слова: бойові обслуги; автоматизовані КП; тренажер; тренажерна система; імітаційна модель; інтенсивна підготовка.

Удосконалювання існуючих та розробка нових автоматизованих систем управління Повітряних Сил ставить підвищені вимоги до рівня підготовки i злагодженості роботи бойових обслуг КП. Одним із напрямків підвищення рівня їх підготовки $\epsilon$ широке застосування тренажерних систем (ТС), за допомогою яких забезпечується моделювання повітряної обстановки, діагностика знань, умінь i навичок у майбутніх фахівців 3 виконання навчальних завдань (Н3), планування i управління процесом інтенсивного навчання. Однак, існуючі тренажерні засоби, як правило, функціонують у демонстраційному режимі, тобто без врахування динаміки зміни рівня підготовки бойових обслуг по виконанню типових НЗ. Практика показує, що можливості традиційних методик навчання таких фахівців обмежені i не можуть забезпечити належної інтенсифікації їх підготовки.

Аналіз останніх досліджень і публікацій [1-3] показує, що на даний час планування тренувань базується на інтуїції досвідченого керівника тренувань. Але відсутність науково обгрунтованих методик та математичних методів щодо планування тренувань призводить до нераціонального використання навчального часу та не досить високого збільшення рівня підготовки бойових обслуг КП. Це пов’язано з тим, що на даний час не достатньо повно висвітлені методичні основи інтенсивної підготовки бойових обслуг, що потребує більш 
детального розглядання цих питань. Вихід полягає в рішучому повороті від екстенсивних до інтенсивних методик навчання [4].

Метою статті $\epsilon$ розробка методичних засад організації інтенсивної підготовки бойових обслуг КП автоматизованих систем Повітряних Сил.

Виклад основного матеріалу дослідження. Діяльність бойових обслуг КП автоматизованих систем Повітряних Сил має ієрархічний характер. Ієрархія полягає в послідовному виконанні бойовими обслугами КП ряду типових операцій. В кожній типовій операції завжди $\epsilon$ чітко виражені критерії виконання, початок і кінець. Критеріями правильності виконання операцій $є$ час виконання, надійність, точність [5].

Крім того, діяльність операторів бойових обслуг КП у цілому характеризується такими показниками, як продуктивність і завантаженість.

Під продуктивністю оператора $\left(\mu_{o}\right)$ розуміється максимально можлива кількість навчальних завдань, що він може вирішувати за одиницю часу при дотриманні наступних умов: якість вирішення завдань, яка характеризується ймовірністю їх своєчасного й безпомилкового виконання $P\left(\mu_{o}\right), \epsilon$ достатньо висока; режим роботи оператора, що залежить від його завантаження $\rho_{0}$, оптимальний [6].

Формально зазначені умови мають вигляд:

$$
\begin{aligned}
P_{o} & \leq P\left(\mu_{o}\right) \leq 1, \\
\rho_{\text {min }} & \leq \rho_{0} \leq \rho_{\text {max }} .
\end{aligned}
$$

Граничні значення величин $P_{o}, \rho_{\min }, \rho_{\max }$ задаються 3 урахуванням специфіки й важливості розв'язуваних завдань, психофізіологічних особливостей діяльності оператора та інше.

Таким чином, для оцінки продуктивності людини-оператора $\mu_{o}$ необхідно мати залежності виду $P\left(\mu_{o}\right)$.

Для аналітичної оцінки величини $P\left(\mu_{o}\right)$ зробимо одне істотне допущення. Припустимо, що ймовірність правильного й своєчасного рішення завдань $P(\mu)$ залежить тільки від наявності часу, тобто при досить великій кількості часу завдання буде вирішене правильно, а нерозв'язних завдань немає.

При зробленому припущенні для розрахунку величини $P\left(\mu_{o}\right)$ стає очевидною доцільність вибору теорії масового обслуговування, що враховує співвідношення між наявним і необхідним для рішення завдань часом.

3 метою дослідження динаміки вирішення навчальних завдань людинаоператор може бути інтерпретована одноканальною системою масового обслуговування (CMO) з наступними специфічними особливостями: вхідний потік заявок включає потоки заявок декількох типів, кожний з яких має свою інтенсивність $\lambda_{i}$, важливість $C_{i}$, час обслуговування $\tau_{i}$ й припустимий час очікування в черзі $t_{i o u}^{n p}$ (перебування в системі $t_{i n p}$ ); порядок обслуговування заявок пріоритетний; система масового обслуговування $B_{i}(\tau)$, як правило, не $\epsilon$ експоненціальною; припустимий час очікування в черзі $t_{i o u}^{n p}$ (перебування в 
системі $t_{i n p}$ ) випадковий й визначається характером завдань розв'язуваних оператором КП [6].

Проведемо більш докладний аналіз вихідних даних, необхідних для дослідження діяльності оператора при його інтерпретації системою масового обслуговування.

1. Вхідний потік заявок. Експериментально доведено, що потік завдань, розв'язуваних фахівцем УПР у процесі роботи, - найпростіший.

2. Пріоритет обслуговування заявок. Вибір типу пріоритетної системи масового обслуговування для дослідження діяльності оператора повністю визначається характером його діяльності й числовими характеристиками розв'язуваних завдань: важливістю $C_{i}$, а також величинами $\tau_{i}, t_{i o q}^{n p}, t_{i \text { доn }}, i=\overline{1, n}$. Залежно від цих факторів модель діяльності оператора КП може бути інтерпретована безпріоритетною СМО або СМО з відносними, абсолютними або динамічними пріоритетами.

3. Розподіл часу обслуговування.

Кожний $i$-ий потік заявок описується характеристиками: інтенсивністю потоку $\lambda_{i}(i=1, n)$; функцією розподілу тривалості обслуговування $B_{i}(\tau)$ iз числовими характеристиками $\bar{\tau}_{i}$ й $\sigma_{i}$; функцією розподілу припустимої тривалості очікування початку обслуговування $F_{i}(t)$ із середнім значенням

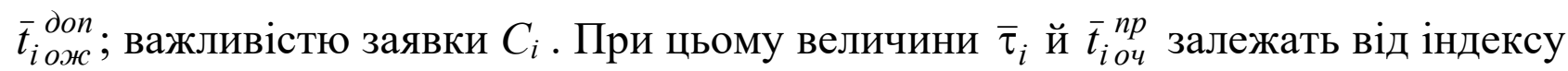
$I$, а важливість завдань приблизно однакова. Тоді роботу оператора КП можна розглядати як обслуговування ним сумарного потоку заявок, що, будучи утворений суперпозицією найпростіших потоків, сам $\epsilon$ найпростішим. Обслуговування заявок сумарного потоку здійснюється в порядку їхнього надходження, а його характеристики визначаються співвідношеннями [6]:

$$
\begin{array}{rlrl}
\Lambda & =\sum_{i=1}^{n} \lambda_{i} ; & \bar{\tau}=\frac{1}{\Lambda} \sum_{i=1}^{n} \lambda_{i} \bar{\tau}_{i} ; \\
\nu=\frac{1}{\bar{t}_{\text {ou }}^{n p} ;} & \bar{t}_{\text {ож }}=\frac{1}{\Lambda} \sum_{i=1}^{n} \lambda_{i} \bar{t}_{i o u}^{n p} ; \\
\rho=\Lambda \bar{\tau} ; & \alpha=v \bar{\tau} .
\end{array}
$$

Як показують результати експериментальних досліджень, прискорене відтворення повітряної обстановки на засобах відображення КП навчальнотренувального центру Повітряних Сил забезпечує організуючий вплив емоціогенних факторів. При завантаженні оператора по виконанню навчальних завдань у межах $\rho_{\min } \leq \rho_{i} \leq \rho_{\max } S$-напруженість позитивно впливає на роботу людини-оператора й сприяє максимальному підвищенню його продуктивності. При цьому, як показано в [7], залежність ймовірності безпомилкового виконання навчальних завдань $i$-го типу $\left(P_{\mathrm{i}}\right)$ від $\rho_{i}$ приймає вид

$$
\text { при } \rho_{i} \leq \rho_{\text {max }}, \quad P_{0 i}>0,5 \quad P_{i}=P_{0 i}+\frac{\left(1-P_{0 i}\right)\left(\rho_{i}-\rho_{\min i}\right)}{\rho_{\max i}-\rho_{\min i}},
$$


де $\rho_{i}-$ завантаження оператора по виконанню навчальних завдань $i$-го типу;

$P_{0 i}-$ ймовірність безпомилкового виконання навчальних завдань $i$-го типу при мінімальному завантаженні оператора $\left(\rho_{\min i}\right)$.

Після досягнення максимального завантаження $\rho_{\max i}$ вплив $S$-напруженості на оператора приводить до дезорганізації його дій, зниженню його продуктивності й збільшенню числа помилок:

при $\rho_{i}>\rho_{\text {max }}, \quad P_{0 i}>0,5 \quad P_{i}=P_{0 i}-\left(1-P_{0 i}\right)$.

Одним із напрямків усунення зазначених недоліків $\epsilon$ розробка математичного апарату планування та організації проведення тренувань, за допомогою якого на кожному етапі навчання з урахуванням досягнутого рівня підготовки операторів забезпечується оптимальне планування тренувань та змістовне наповнення процесу відпрацювання Н3 різних типів. При цьому процес функціонування тренажерної системи являє собою керований $N$-етапний динамічний процес, який на кожному (n-му) етапі характеризується двома видами параметрів - параметрами керування $\lambda_{n}$ (інтенсивністю імітації тактичних ситуацій для відпрацювання типових Н3) і параметрами стану $G_{n}\left(\lambda_{n}\right)$ (рівнем підготовки операторів бойових обслуг по виконанню Н3) [8]. У якості обмеження виступає сумарне навантаження на оператора по виконанню типових операцій $\left(\rho_{\max }\right)$.

У моделі функціонування ТС, залежно від фактичних рівнів підготовки операторів, визначаються необхідні прогнозовані рівні їх підготовки 3 виконання $n$ типів НЗ при відтворенні тактичних ситуацій з інтенсивністю $\lambda_{n}$. Виходячи 3 цього, передбачається, що загальний час тренування підрозділяється на $N$ етапів, кожен 3 яких характеризується певною інтенсивністю відтворення типових тактичних ситуацій $\lambda_{n}(n=\overline{1, N})$, на які оператори реагують виконанням типових операцій Н3 на автоматизованих робочих місцях КП. Інтенсивність потоку ситуацій змінюється від етапу до етапу в наростаючому підсумку:

$$
\lambda_{1}<\lambda_{2}<\cdots<\lambda_{n}<\cdots<\lambda_{N} \cdot(5)
$$

Кінцевою метою тренувань $\left(W_{N}\right) \epsilon$ досягнення операторами максимально можливого рівня підготовки по виконанню НЗ у найбільш складних умовах повітряної обстановки.

Загалом задача оптимального планування імітованої повітряної обстановки та відпрацювання НЗ різних типів може бути подана наступним чином.

Знайти

$$
\max W_{N}=\sum_{n=1}^{N} G_{n}\left(\lambda_{n}\right)
$$

при

$$
\rho_{N}=\rho_{\max }
$$


де $\rho_{N}$ - навантаження на операторів на протязі $N$ етапів.

Процес підготовки бойових обслуг в часі розбивається на $N$ етапів і характеризується переходом рівня їх підготовки з одного стану в інший.

3 урахуванням дискретного опису процесу керування цільова функція ефективності підготовки операторів КП може бути подана сумою

$$
W_{N}=\sum_{n=1}^{N} G_{n}\left(\lambda_{n}\right)=\frac{1}{N} \sum_{n=1}^{N} P_{n}\left(\lambda_{n}\right),
$$

де $P_{n}\left(\lambda_{n}\right)$ - рівень підготовки операторів по виконанню $n$-го типу НЗ після відтворення імітованих тактичних ситуацій з інтенсивністю $\lambda_{n}$ на $n$-му етапі навчання (визначається експериментально);

$N$ - загальна кількість етапів навчання.

Таким чином, необхідно знайти такі параметри імітованих ситуацій $\lambda_{n}(n=\overline{1, N)}$ для відпрацювання типових Н3 на кожному етапі щоб максимізувати цільову функцію (8) при наступних обмеженнях:

$$
\left.\begin{array}{l}
\lambda_{n}=0,1,2, \ldots, \\
\sum_{n=1}^{N} t_{n} \lambda_{n}=\rho_{\max },
\end{array}\right\}
$$

де $t_{n}$ - час виконання $n$-го типу НЗ (на $n$-му етапі навчання).

Для знаходження оптимальних значень $\left\{\lambda_{n}\right\}$ скористуємося методом динамічного програмування [8].

Позначимо

$$
\max _{m_{1}, \ldots, m_{r}} \sum_{n=1}^{r} G_{n}\left(\lambda_{n}\right)
$$

при умові

$$
\sum_{n=1}^{r} t_{n} \lambda_{n}=\xi
$$

через $\Lambda_{r}(\xi)$.

Після нескладних перетворень переходимо до наступного рекурентного співвідношення динамічного програмування

$$
\Lambda_{r}(\xi)=\max _{\lambda_{r}}\left\{G_{r}\left(\lambda_{r}\right)+\Lambda_{r-1}\left(\xi-t_{r} \lambda_{r}\right)\right\} \quad(r=1, \ldots ., N)
$$

при умові

$$
\lambda_{r_{H . u .}}=\frac{\xi}{t_{r}} .
$$

Характерним для динамічного програмування $є$ визначений методичний підхід, а саме: процес планування імітованої повітряної обстановки поділяється на $N$ етапів і здійснюється послідовна оптимізація кожного з них. На кожному $r$-му етапі з урахуванням усіх можливих припущень результатів попереднього 
етапу обчислюється основне рекурентне співвідношення (12) та визначається умовний оптимальний параметр керування $\lambda_{r}$.

Прийнявши $\xi=\rho_{\max }$ та припустивши у (12) $r=N$, приходимо до співвідношення

$$
\Lambda_{N}\left(\xi=\rho_{\max }\right)=\max _{\lambda_{N}}\left\{G_{N}\left(\lambda_{N}\right)+\Lambda_{N-1}\left(\rho_{\max }-t_{N} \lambda_{N}\right)\right\}
$$

при умові

$$
\lambda_{N_{H . u .}}=\frac{\rho_{\max }}{t_{N}} .
$$

Знайшовши 3 (14) оптимальне значення $\lambda_{N o p t}$ та припустивши $\xi_{1}=\rho_{\max }-t_{N} \lambda_{N o p t}(\rho)$, послідовно, починаючи $3(N-1)$-го етапу, знаходяться оптимальні значення решти змінних: $\lambda_{N-1}, \lambda_{N-2}, \ldots, \lambda_{1}$. Необхідно відзначити, що метод динамічного програмування являє собою направлений послідовний перебір варіантів, що обов’язково приводить до глобального максимуму й оптимального вирішення задачі (6).

Для досягнення кінцевої мети $\left(W_{N}\right)$ з використанням вищезазначеного методичного апарата підготовляється оптимальний план поетапного відпрацювання типових НЗ. На основі застосування адаптивних тренажерних систем операторів КП АСУ для кожного етапу тренувань, поки мета $\left(W_{N}\right)$ не досягнута, повторюється наступна послідовність дій:

відповідно до оптимального плану здійснюється відтворення необхідної імітованої обстановки для послідовного відпрацювання такого набору типових Н3, при якому забезпечується досягнення необхідного (максимального) рівня підготовки бойових обслуг;

на основі порівняння поточного рівня підготовки операторів по виконанню типових задач із необхідним приймається рішення про подальший хід тренування. Якщо поточний рівень не нижче необхідного - тренування продовжується. В інших випадках, в залежності від досягнутого рівня підготовки операторів на $n$-му етапі, виникає необхідність в адаптивній зміні (повторній оптимізації) плану відпрацювання різних типів НЗ. 3 цією метою для кожного етапу тренувань (починаючи 3 n-го) забезпечується формування оптимального набору відпрацювання НЗ 3 урахуванням поточного рівня підготовки операторів КП АСУ Повітряних Сил.

Висновки. Таким чином, за допомогою розробленого методичного апарата планування інтенсивної підготовки операторів на кожному етапі процесу тренувань забезпечується формування та відпрацювання оптимального набору H3 з урахуванням поточного рівня підготовки операторів й обмежень на їх навантаження. При цьому забезпечується досягнення максимального рівня підготовки бойових обслуг автоматизованих систем управління Повітряних Сил по виконанню типових навчальних завдань у найбільш складних умовах повітряної обстановки. 


\section{ЛІТЕРАТУРА}

1. Колотуша В. П. Напрями підвищення якості початкової підготовки диспетчерів УПР / В. П. Колотуша // Педагогічні науки. - 2011. - Випуск 96. - С. 101-110.

2. Харитонов О.Л., А.О. Харитонов Пропозиції щодо вдосконалення управління силами та засобами ппо шляхом підвищення життєвості пунктів управління /О.Л. Х аритонов, А.О. Харитонов // Системи озброєння і військова техніка, 2010, № 2(22) С.77-80

3. Про затвердження Правил штурманського забезпечення польотів державної авіації України. Наказ МО України від 23.02.2016 № 100. - Режим доступу: https://zakon.rada.gov.ua/laws/show/z0418-16

4. Шворов С.А. Сілко О.В. Теоретичні питання побудови інтелектуальних тренажерних систем інтенсивної підготовки операторів АСУ військового призначення Збірник наукових праць ВITI НТУУ „КПІ” № 1 - 2011. С. 179-182. - Режим доступу: http://www.viti.edu.ua/files/zbk/2011/24 1 2011.pdf

5. Герасимов Б.М. Методика комплексної оцінки і вибору раціонального варіанту тренажерно-імітаційного комплексу / Б.М. Герасимов, О.Ю. Казанцев //Вісник ВІТІ НУТУ «КПІ». -2002 - №3. - С.23-28.

6. Шворов С.А. Модель інтенсивної підготовки фахівців автоматизованих комплексів контролю повітряного простору / Шворов С.А.,Чепуренко В.В., Андрійченко С.М. // Збірник наукових праць Військового інституту Київського національного університету імені Тараса Шевченка. - 2006.- Вип. 2. - С. 142-146.

7. Побудова та використання систем дистанційного навчання з елементами штучного інтелекту: Монографія [Лєнков С.В., Гахович С.В., Гунченко Ю.О., Лукін В.С., Шворов С.А.]. - Одеса, Вид-во ВМВ, 2013. - 324 с.

8. Зайченко Ю.П. Исследование операций: Учеб. Пособие для студентов вузов. - 2-е изд., перераб и доп. / Ю.П. Зайченко - Киев: «Вища школа». Головное изд-во, 1979. - 392 с.

\section{REFERENCES}

1. Kolotusha V. P. Napriamy pidvyshchennia yakosti pochatkovoi pidhotovky dyspetcheriv UPR / V. P. Kolotusha // Pedahohichni nauky. - 2011. - Vypusk 96. - S. 101-110.

2. Kharytonov O.L., A.O. Kharytonov Propozytsii shchodo vdoskonalennia upravlinnia sylamy ta zasobamy ppo shliakhom pidvyshchennia zhyttievosti punktiv upravlinnia/O.L. Kh arytonov, A.O. Kharytonov // Systemy ozbroiennia i viiskova tekhnika, 2010, № 2(22) S.77-80

3. Pro zatverdzhennia Pravyl shturmanskoho zabezpechennia polotiv derzhavnoi aviatsii Ukrainy. Nakaz MO Ukrainy vid 23.02.2016 № 100. - Rezhym dostupu: https://zakon.rada.gov.ua/laws/show/z0418-16

4. Shvorov S.A. Silko O.V. Teoretychni pytannia pobudovy intelektualnykh trenazhernykh system intensyvnoi pidhotovky operatoriv ASU viiskovoho pryznachennia Zbirnyk naukovykh prats VITI NTUU „KPI” № 1 - 2011. S. 179-182. - Rezhym dostupu: http://www.viti.edu.ua/files/zbk/2011/24_1_2011.pdf

5. Herasymov B.M. Metodyka kompleksnoi otsinky i vyboru ratsionalnoho variantu trenazherno-imitatsiinoho kompleksu / B.M. Herasymov, O.Iu. Kazantsev//Visnyk VITI NUTU «KPI». - 2002 - №3. - S.23-28.

6. Shvorov S.A. Model intensyvnoi pidhotovky fakhivtsiv avtomatyzovanykh kompleksiv kontroliu povitrianoho prostoru / Shvorov S.A.,Chepurenko V.V., Andriichenko S.M. // Zbirnyk naukovykh prats Viiskovoho instytutu Kyivskoho natsionalnoho universytetu imeni Tarasa Shevchenka. - 2006.- Vyp. 2. - S. 142-146.

7. Pobudova ta vykorystannia system dystantsiinoho navchannia $\mathrm{z}$ elementamy shtuchnoho intelektu: Monohrafiia [Lienkov S.V., Hakhovych S.V., Hunchenko Yu.O., Lukin V.Ie., Shvorov S.A.]. - Odesa, Vyd-vo VMV, 2013. - 324 s.

8. Zaichenko Yu.P. Yssledovanye operatsyi: Ucheb. Posobye dlia studentov vuzov. - 2-e yzd., pererab y dop. / Yu.P. Zaichenko - Kyev: «Vyshcha shkola». Holovnoe yzd-vo, 1979. - 392 s. 


\section{РЕЗЮМЕ}

Сергей Шворов, доктор технических наук, профессор Национальный университет биоресурсов и природопользования

Сергей Горбачевский, кандидат технических наук, старший научный сотрудник Национальный университет обороны Украины имени Ивана Черняховского

Михаил Орда, кандидат технических наук, старший научный сотрудник

Национальный университет обороны Украины имени Ивана Черняховского

\section{Методические основы организации интенсивной подготовки боевых расчетов КП в учебно-тренировочных центрах воздушных сил}

В статье рассмотрены методические основы планирования и реализачии интенсивной подготовки боевых расчетов автоматизированных командных пунктов Воздушных Сил Украины, практическое использование которых обеспечивает повышение эффективности проведения комплексных тренировок в учебно-тренировочных центрах Воздушных Сил Украины на основе интенсификации отработки учебных задач.

Ключевые слова: боевые расчеты; автоматизированные командные пункты; тренажер; тренажерный система; имитаџионная модель; интенсивная подготовка.

\section{SUMMARY}

Sergey Shvorov, doctor of technical sciences, professor National University of Life and Environmental Sciences

Serhii Horbachevsky, $\mathrm{PhD}$ (technical sciences), Senior Researcher National University of Defence of Ukraine Named after Ivan Chernyakhovskyi

Mikhailo Orda,

$\mathrm{PhD}$ (technical sciences), Senior Researcher National University of Defence of Ukraine Named after Ivan Chernyakhovskyi

\section{Methodological principles of organization of intensive training of combat services of command points in training centers of the Air Force}

The article considers the methodological principles of planning and implementation of intensive training of combat services of automated command posts of the Air Force, the practical use of which provides increased efficiency of comprehensive training in training centers of the Air Force on the basis of intensification of training tasks.

Key words: combat services; automated command posts; simulator; training system; simulation model; intensive training. 